\title{
EXPERIMENTAL AND NUMERICAL INVESTIGATIONS OF ULTIMATE STRENGTH OF IMPERFECT STIFFENED PLATES OF DIFFERENT SLENDERNESS
}

\author{
Krzysztof Woloszyk \\ Gdansk University of Technology, Faculty of Ocean Engineering and Ship Technology, Poland \\ Yordan Garbatov \\ Centre for Marine Technology and Ocean Engineering (CENTEC), Instituto Superior Técnico, Universidade de Lisboa, Portugal \\ Jakub Kowalski \\ Gdansk University of Technology, Faculty of Ocean Engineering and Ship Technology, Poland \\ Leszek Samson \\ Gdansk University of Technology, Faculty of Ocean Engineering and Ship Technology, Poland
}

\begin{abstract}
The objective of this study is to analyse the behaviour of compressed stiffened plates of different slenderness using experimental and numerical methods. The presented results are part of a long-term project to investigate the ultimate strength of geometrically imperfect structures subjected to different degradation phenomena, including corrosion degradation and locked cracks. Several specimens were subjected to a uniaxial compressive force, and the most important quantities related to the structural behaviour were captured and analysed. A finite element model, accounting for material and geometrical nonlinearities and initial geometrical imperfections, was developed using the commercial software ANSYS. The residual welding-induced stresses were measured in the middle cross-section for two specimens. The initial imperfection was identified by employing a close-range photogrammetry approach. It was concluded that the numerical analyses, based on the finite element model, predict the ultimate strength of stiffened plates accurately, although some deviations were also observed. The detailed analysis with the indication of possible uncertainty is presented, and several conclusions are derived.
\end{abstract}

Keywords: Stiffened Plate,Ultimate Strength,FEM,Boundary conditions

\section{INTRODUCTION}

Ultimate strength analysis is currently one of the fundamental types of structural assessment considering ship and offshore structures. Nowadays, the most commonly used method is the non-linear finite element method [1]. A static solver is used, including a convergence iterator using the Newton-Raphson methods, including Riks arc-length one. A benchmark study in [2] showed that various analysts who participated in the benchmark study, having the same initial parameters of the FE model, presented results with relatively high scatter. The conclusion was that more validation through experimental work is needed.

The development of numerical tools is still progressing, and experimental investigations are the most valuable for predicting the ultimate strength of different structural components. The experimental results are typically used to validate other numerical methods. The most useful are full-size experiments, e.g., with the destroyer Albuera [3], and now large-scale experiments [4]. However, due to the very high costs and problems with the loading application, reduced-scale experiments are more frequently conducted, usually in the form of a box girder. Apart from hull girder tests, investigations of reduced models, i.e., stiffened panels, stiffened plates, and plates, are frequently performed.

The structural components that compose the ship hull are plates and stiffened plates. The primary role of plates is to support the external sea pressure and internal cargo pressure and transfer the load into the stiffeners and primary supporting members. Such members can be subjected to 
different loads, such as longitudinal, axial and lateral loads. Series of experiments on plates subjected to different types of loading may be found, for example, in [5], and numerical analysis e.g. in [6]. Based on that, different empirical formulations were proposed.

The fundamental structural component that resists longitudinal loads during ship bending is the stiffened plate, which is composed of a stiffener with attached plating. The stiffened plate typically spans between two rigid transverse frames. The series of adjacent stiffened plates between two longitudinal girders forms a stiffened panel. When considering typical aspect ratios of the stiffened plates, the structural behaviour of a single stiffened plate is relatively independent of the adjacent stiffened plates. The investigation of these components typically allows the ultimate strength of the entire ship hull girder to be assessed. A significant number of experiments were carried out in the 1970s, such as [7]. Other recent experiments and numerical analyses concerning both stiffened plates and panels can be found in $[8,9]$.

Small-scale specimen tests of ship hull girders modelled as box girders have also been performed. However, the number of stiffeners and geometrical similarity is hard to satisfy when compared to a full-scale ship. Thus, the transfer of the results obtained on a real scale is still challenging. Nevertheless, such experiments are highly useful in validating numerical codes, especially the FE analyses. One of the first attempts at experimental analysis using a box girder was performed in [10]. Studies investigating small-scale box girders representing a ship hull were conducted, such as a series of experiments in [11-13] and on a large-scale specimen in [14]. Wang et al. [15] tested a hull model of three longitudinal box girders on a deck subjected to pure bending.

The presented results are part of a project that aims to investigate the ultimate strength of geometrically imperfect structures subjected to different degradation phenomena, such as corrosion and cracks. To establish a reliable numerical model, this study aims to validate the finite element model with experimental results through a detailed investigation of different governing input parameters, such as mechanical properties, level of initial imperfections and residual stresses. In this case, three stiffened plates without any degradation effects were tested, to quantify the structural behaviour in a non-degraded state. The initial imperfection was identified by employing a close-range photogrammetry approach. The relevant information, such as the force-displacement relationship, lateral mid-displacement, and strains in the mid-cross-section, was captured during the loading process and analysed. A numerical model, taking into account the actual mechanical properties and initial imperfections of the specimen, was created and validated with the existing experimental results.

\section{EXPERIMENTAL SET-UP}

Stiffened plates made of normal strength steel (minimum yield stress of $235 \mathrm{MPa})$ with three different thicknesses $(5,6$, and $8 \mathrm{~mm}$ ) were tested, where the plate and the stiffener are of the same thickness. The stiffened plates were $1,260 \mathrm{~mm}$ long and $400 \mathrm{~mm}$ wide with the stiffener $100 \mathrm{~mm}$ in height. To avoid excessive post-welding residual stresses, automatic arc-welding was performed with the welding sequence presented in Fig. 2 (left). The mechanical properties of the steel are obtained through tensile testing of three dog-bone shaped specimens for each plate thickness, and the results are summarised in Table 1 . The information related to the experimental set-up was provided in [16], which provides an analysis of the impact of the boundary conditions. In experimental testing, the incremental loading has been produced by a hydraulic jack-up subjected to the bottom support. The quasi-static conditions have been provided by the very slow increment of the load. Fig. 1 presents the distribution of both mounted strain and displacement gauges. Clamped boundary conditions were employed, and were analysed in the pre-experimental numerical investigations, including the interaction between the supports and specimen, as reported in [17].

Tab. 1. Mechanical properties

\begin{tabular}{|c|c|c|c|c|}
\hline 总 & 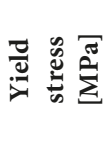 & 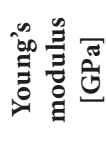 & 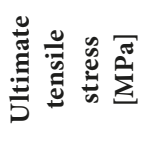 & 㞼 \\
\hline 5 & 263.2 & 199.0 & 386.5 & 0.278 \\
\hline 6 & 279.3 & 190.6 & 404.8 & 0.267 \\
\hline 8 & 357.5 & 196.7 & 457.0 & 0.224 \\
\hline
\end{tabular}
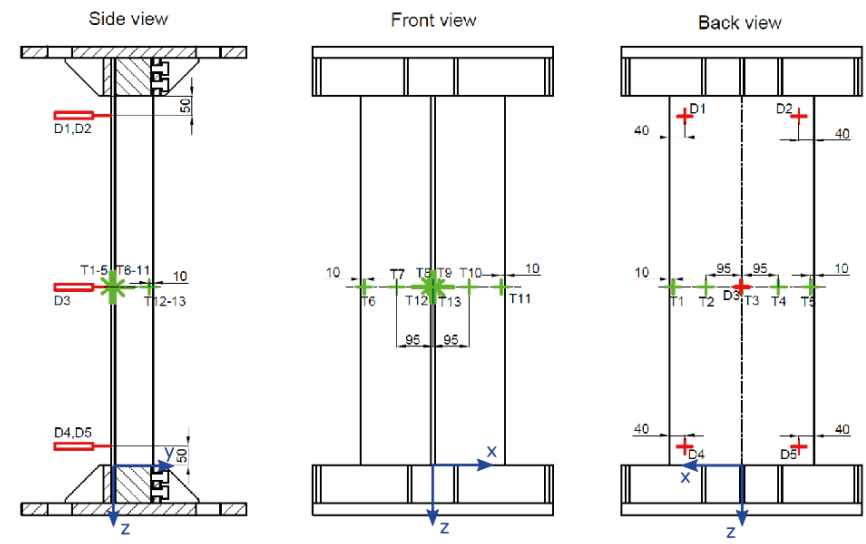

Fig. 1. Strain gauges and displacement transducers (strain gauges - green, displacement gauges - red) [16]

Both the plate slenderness and the column slenderness ratios are the primary factors that govern the ultimate strength of stiffened plates [18]. The plate slenderness ratio is defined as:

$$
\beta=\frac{b}{t} \sqrt{\frac{R_{e}}{E}} \#(1)
$$


where $b$ is the plate width, $t$ is the plate thickness, $R_{e}$ is the yield stress of the material and $E$ is Young's modulus. The column slenderness ratio is equal to:

$$
\lambda=\frac{l}{\pi \sqrt{\frac{I}{A}}} \sqrt{\frac{R e}{E}} \#(2)
$$

where $l$ is the plate length, $I$ is the moment of inertia of the plate with the attached stiffener and $A$ is the cross-sectional area of the stiffened plate.

The resulting plate and column slenderness ratios of the tested specimens, considering the actual values of mechanical properties, are presented in Table 2. When comparing these values with those typically observed in ship structures [18], the plate slenderness ratio can be considered as relatively high, and the column slenderness is within the mean range.

Tab. 2. Characteristics of tested stiffened plates

\begin{tabular}{|c|c|c|}
\hline $\begin{array}{c}\text { Thickness } \\
{[\mathbf{m m}]}\end{array}$ & $\begin{array}{c}\text { Plate slenderness ratio } \\
{[-]}\end{array}$ & $\begin{array}{c}\text { Column slenderness ratio } \\
{[-]}\end{array}$ \\
\hline 5 & 2.91 & 0.499 \\
\hline 6 & 2.55 & 0.522 \\
\hline 8 & 2.13 & 0.576 \\
\hline
\end{tabular}

Welding-induced distortions and residual stresses in stiffened panels may affect their ultimate strength. To determine the level of welding-induced residual stresses, nondestructive testing in the section located at a half-length of the $5 \mathrm{~mm}$ and $8 \mathrm{~mm}$ stiffened plates, where the maximum level is observed, was carried out employing MagStress $5 \mathrm{c}$ apparatus developed by NNT laboratory, which utilises the Barkhausen effect [19] resulting in the full information on the stress distribution (main stress components and their orientation in all the investigated points. The welding technique has been identical for each plate. Thus, it was identified that the residual welding stresses could be measured for maximum and minimum thickness of the plate, providing sufficient information about the impact of this effect. The points where the welding-induced residual stresses were measured are presented in Fig. 2 (right).
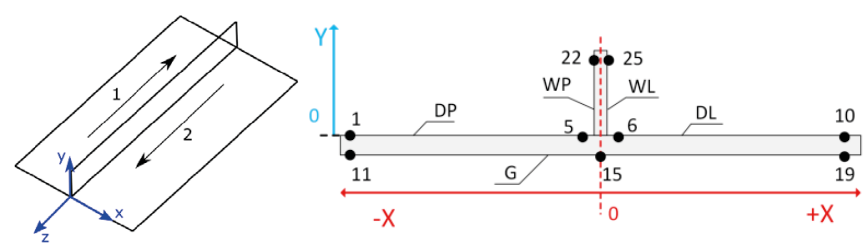

Fig. 2. Applied welding sequence (left) and the measured points of weldinginduced residual stresses (right)

At each point, the stresses in both the longitudinal (Sx) and transverse (Sy) directions were measured. The residual stresses in the plate element for the $5 \mathrm{~mm}$ and $8 \mathrm{~mm}$ specimens are presented in Fig. 3, considering both the upper (DP, DL) and lower $(\mathrm{G})$ surfaces of the plate. It should be noted that the residual stresses near the welding zone (points 5 and 6) were measured approx. $2.5 \mathrm{~cm}$ from the symmetrical axis, due to the width of the gauging probe. However, the residual stresses in the longitudinal direction, in the welding zone, are reaching the level of the yield stress of the material [20]. Thus, the residual stress level in that region is assumed as equal to the yield stress.

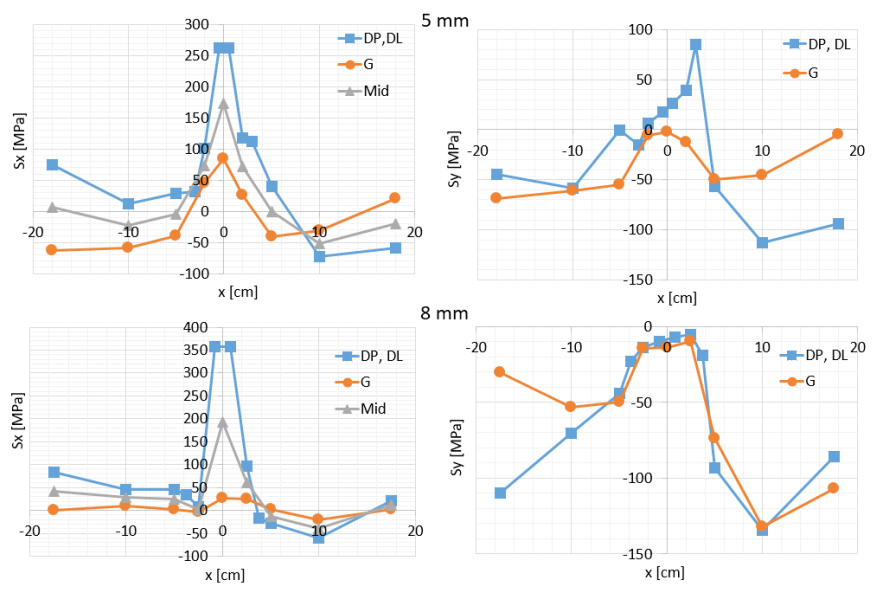

Fig. 3. Welding-induced residual stresses, plate element of $5 \mathrm{~mm}$ (top) and $8 \mathrm{~mm}$ (bottom) thickness

The distribution of the welding-induced residual stresses in the longitudinal direction is similar to that typically observed in [20]. The region of high tensile stresses is observed near the welding zone, whereas the compressive stresses are observed away from that region. However, when considering the $5 \mathrm{~mm}$ stiffened plate, there are significant differences between the residual stresses on the top and bottom surface, which indicates that the plate areas near the specimens' free edges are subjected to local bending from the beginning of the loading process. Additionally, the bending direction is opposite on both sides of the stiffener. Furthermore, it can be seen that the distribution of compressive stresses is asymmetrical, which is a result of the applied welding sequence. However, in the case of the $8 \mathrm{~mm}$ specimen, the bending stresses are less significant, which is caused by the lower plate slenderness ratio compared to the $5 \mathrm{~mm}$ plate. In the case of the stresses in the transverse direction, the compressive stresses exist in the regions away from the welding zone, whereas in the welding zone the transverse stresses are close to zero in the case of both specimens.

As it was discussed in [20], the parameter used to determine either the residual stresses will have a significant impact or not is used the ratio between the mean compressive stresses and the yielding stress of the material. The higher the compressive stresses are; the potential decrease of the ultimate strength is also higher. The estimated compressive stresses are $7.0 \%$, and $4.4 \%$ of yield stress for $5 \mathrm{~mm}$ and $8 \mathrm{~mm}$ stiffened plates, respectively. Based on the analysis of the welding-induced residual stresses, it may be concluded that these are rather insignificant, and they are not taken into account in the numerical analysis. 


\section{FE ANALYSIS}

The commercial software ANSYS [21] is used in the present analysis, employing the non-linear FE methods using a static implicit solver and the arc-length iterative procedure. For modelling the bending behaviour of the plate elements, fournode shell elements are used, denoted as SHELL181. The bilinear relationship with hardening is used as a material model, and the material properties are considered as presented in Table 1, depending on the thickness of the analysed specimen. The tangent modulus of linear hardening was considered equal to E/500. The proposed model is sufficient for the study since it was shown in [22] that the ultimate tensile stress has almost no impact on the ultimate strength of stiffened plates. The mechanical properties that mostly govern the ultimate capacity are the yield stress and Young's modulus; thus, the multilinear stress-strain relationship is not needed. The calculation procedure takes into account both material and geometrical nonlinearities. The latter is considered due to the existence of high deflections of both the plates and the stiffener caused by the buckling and further plastic collapse.

Initial imperfections $[23,24]$ are among the most critical parameters that govern the ultimate strength of stiffened plates. Thus, these were measured using the photogrammetry technique [25]. The detailed information about the measurements can be found in [26] (see Fig. 4). The point cloud generated was further transformed into a regular mesh with the use of specially developed code.

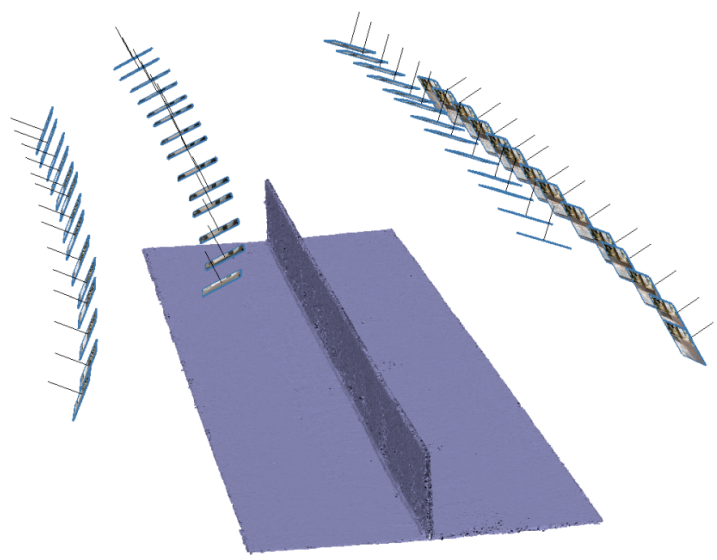

Fig. 4. Cloud of specimen surface and positions where photographs are taken [26]

The initial imperfections were applied to the numerical model by changing the $\mathrm{z}$-coordinate of each node. The shapes of the initial imperfections for the three considered specimens are presented in Fig. 5, compared to the shape of perfectly flat plates.
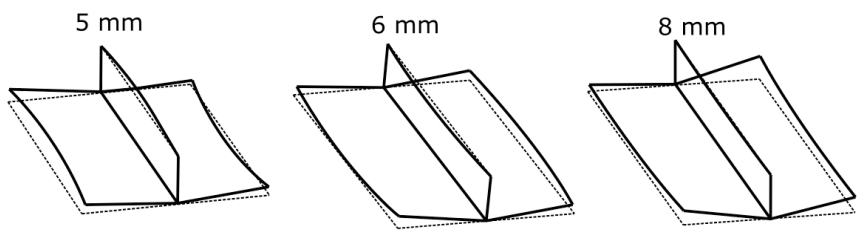

Fig. 5. Initial imperfections of specimens (scale factor 5x)

In general, the imperfections may be described as a superposition of two types. The first one is a general imperfection, which results in a global sideways distortion of the plate element, leading to a V-shape at both ends of the stiffened plate. The second one is a local imperfection resulting in distortions in the shape of a half sine-wave on both sides of the stiffener. One can see that with the increase of the plate thickness, the global imperfections are more dominant, whereas the local imperfections are less significant. The shapes are consistent with the measured welding-induced residual stresses. In the case of the $5 \mathrm{~mm}$ specimen, the local imperfections are significant, which results in pre-existing bending stresses in opposite directions. In the case of the $8 \mathrm{~mm}$ specimen, one side is almost flat (which results in no bending stresses) and the second one is slightly curved (which results in considerable bending stresses). One needs to be aware, that the clamping of the specimens could change the initial imperfections of the specimen as presented in Fig. 5. Thus, before the loading, the strains and deflections, as presented in Fig. 1 were measured during the clamping procedure. There was identified that imperfections decreased slightly, whereas stresses increased. However, their level was marginal concerning both initial imperfections and welding residual stresses levels. Thus, it was concluded, that clamping of the specimen won't have a significant impact on the initial specimen state. The maximum local imperfections are about $6 \mathrm{~mm}, 4.5 \mathrm{~mm}$, and $2.5 \mathrm{~mm}$ for the $5 \mathrm{~mm}, 6 \mathrm{~mm}$, and $8 \mathrm{~mm}$ stiffened plates, respectively. Thus, these cannot be neglected during finite element modelling. Due to the nonsignificant impact of clamping on the initial imperfections of the stiffened plates, the initial imperfections were applied to the FE model as-measured.

The experimental boundary conditions are reflected, and the model of the stiffened plate with the considered restrained DOFs is presented in Fig. 6 (left). Both stiffener and plate are clamped. The loading is generated via an incremental application of the longitudinal shortening to the upper edge of the specimen.
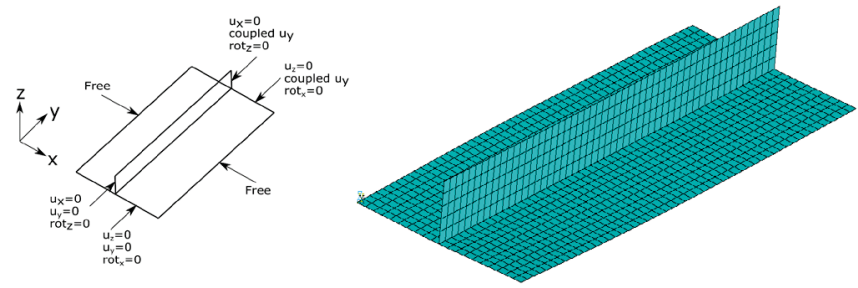

Fig. 6. Applied boundary conditions (left) and FE model of the specimen (right) 
To find the proper mesh density, convergence studies were carried out. It was found that the element size of $20 \mathrm{~mm}$ provides sufficient accuracy, leading to a not too long computational time. The FE model, with the generated mesh of the considered element size, is presented in Fig. 6 (right).

\section{EXPERIMENTAL RESULTS}

The experimental results for the three specimens of different stiffness are presented in the form of force-displacement curves, as can be seen in Fig. 7. With the increase of the plate thickness, the inclination of the force-displacement curve is higher due to the rise of the specimen's in-plane stiffness (the extent to which the element can resist deformation or deflection under the subjected load). The point of the ultimate capacity was reached for a longitudinal shortening of $5 \mathrm{~mm}$ in the case of the $6 \mathrm{~mm}$ and $8 \mathrm{~mm}$ specimens. In the case of the $5 \mathrm{~mm}$ stiffened plate, the maximum force was reached at the level of $7 \mathrm{~mm}$ of longitudinal displacement. At the beginning of loading, the behaviour is not stable, which could be the result of the fixing of the specimens in the support at the beginning of the loading process. Furthermore, in the case of the $5 \mathrm{~mm}$ specimen, the exact bifurcation point can be seen, with an axial force of $240 \mathrm{kN}$, whereas, when considering the $6 \mathrm{~mm}$ and $8 \mathrm{~mm}$ specimens, the exact bifurcation point cannot be traced. This can be possibly caused by the higher slenderness ratio of the $5 \mathrm{~mm}$ stiffened plate. In general, the post-collapse behaviour was similar in all three specimens.

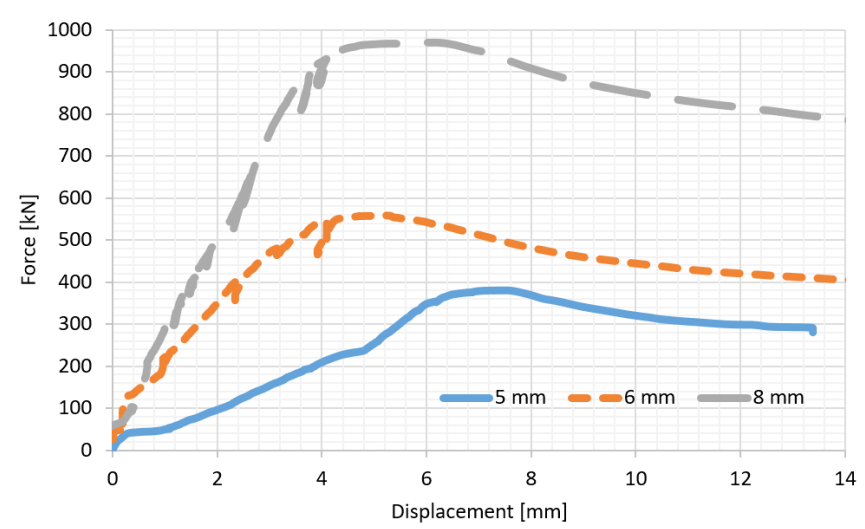

Fig. 7. Force-displacement curves for tested specimens

The longitudinal membrane strains in the mid-crosssection are evaluated, and the strain gauges' measurements are analysed (see Fig. 8). Two steps of the incremental load are chosen, one in the elastic stage and the other when the ultimate capacity is reached. For all specimens, the transition of longitudinal loads is non-uniform. The region near the welding transmits most of the load, with a much higher rigidity than the rest of the specimen. The free edges of the stiffened plate have the highest imperfection level, and the in-plane stiffness is low from the beginning; additionally, there are not restrained from a deflection. However, the plate in the welding region is relatively flat, and due to the connection with the stiffener, which forms a T-shape, it is much more resistant to the out-of-plane bending.

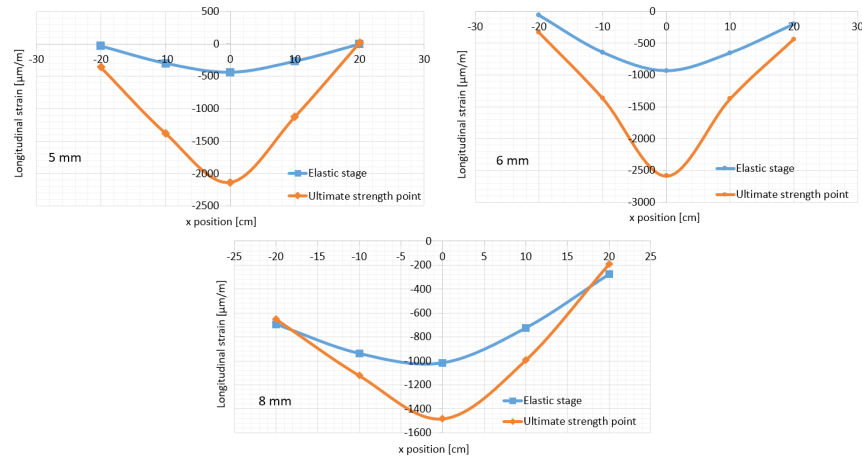

Fig. 8. Longitudinal strain distributions, mid-cross-sections of the specimens

Fig. 9 shows the lateral mid-displacements of the specimens, which increase up to a point where the ultimate capacity is reached in all specimens. The negative displacement indicates that it is increasing towards the stiffener. After reaching the ultimate strength, the displacements decrease and the final values go to the opposite sign in the case of the $5 \mathrm{~mm}$ and $8 \mathrm{~mm}$ stiffened plates. This behaviour indicates that in all cases the collapse is caused by the secondary effects (i.e., local plate buckling and stiffener tripping) and that global column buckling has not occurred. It is also notable that in the case of the $6 \mathrm{~mm}$ and $8 \mathrm{~mm}$ specimens, the displacements are much higher than that of the $5 \mathrm{~mm}$ specimen.

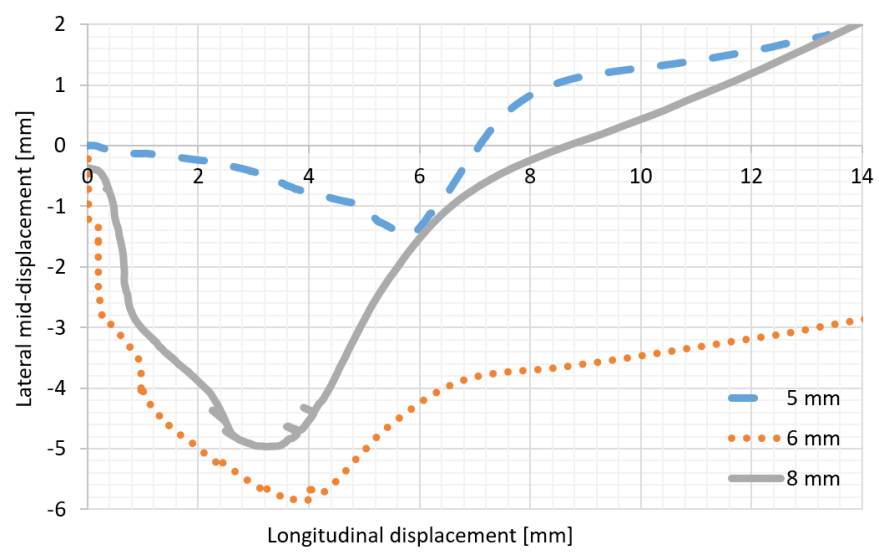

Fig. 9. Lateral mid-displacements of the specimens

The post-collapse shapes are analysed as presented in Fig. 10. The deflection forms of the specimens are somewhat similar. During the experimental testing, it was observed that firstly the plate buckled on both sides of the stiffener, having deflections in opposite directions. Then the plate buckling forced the rotation of the cross-section, and stiffener tripping occurred. Finally, the critical cross-section crossed the level of the yield point of the material, and the stiffened plate was not able to carry any more load. Thus, the complex elastoplastic collapse mode was observed, where plate buckling followed by stiffener tripping was the trigger to cause the loss of the structural capacity. Global column buckling did not occur in the analysed cases. 


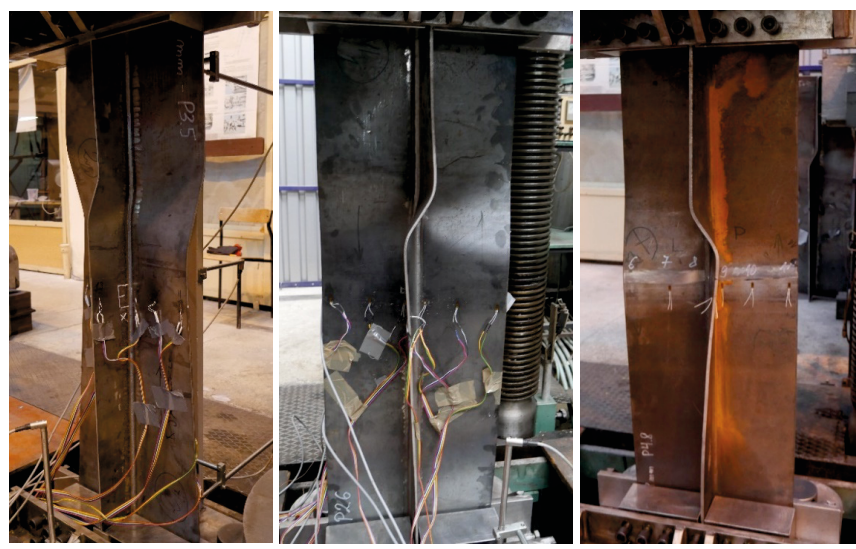

Fig. 10. Post-collapse shape for $5 \mathrm{~mm}$ (left), $6 \mathrm{~mm}$ (mid) and $8 \mathrm{~mm}$ (right) specimens

\section{COMPARISON BETWEEN NUMERICAL AND EXPERIMENTAL RESULTS}

The force-displacement relationships as estimated by the FE analyses and experimental tests are compared. The ultimate strength was reached, for the longitudinal shortening, between 5 and $7 \mathrm{~mm}$. In the case of the numerical results, this point was reached with $2 \mathrm{~mm}$ of shortening. The readjustment of the test set-up may explain this until every part of the stiffened plate, supports and hydraulic machine were in full contact, and the experimental supports start to behave like those generated by FEM. Cui and Wang [27] suggested that when the displacement is measured only in the head, which transmits the load, the other supporting structure, since it is not perfectly rigid, is also subjected to some deflections and this increases the shortening measurements. An additional displacement transducer was installed to measure the relative displacement between the supports. It was found that there were no significant differences between the two readings and the upper head was rigid enough (it does not deform under the considered load).

The longitudinal displacement was divided by a factor between 2 and 3.5, depending on the specimen, to adjust the numerical and experimental results, as presented in Fig. 11. When comparing the numerical and experimental results, the structural behaviour is quite similar, including the pre- and post-collapse regime, especially when considering the $6 \mathrm{~mm}$ specimen. Nevertheless, in the case of both the $5 \mathrm{~mm}$ and $8 \mathrm{~mm}$ specimens, some differences were notable; in the precollapse behaviour, the force displacement-curve inclination is smaller at the beginning of the loading process, up to the level of approximately $50 \%$ of the maximum force. Furtherly, it is increasing, leading to a similar displacement at the point of the maximum capacity.

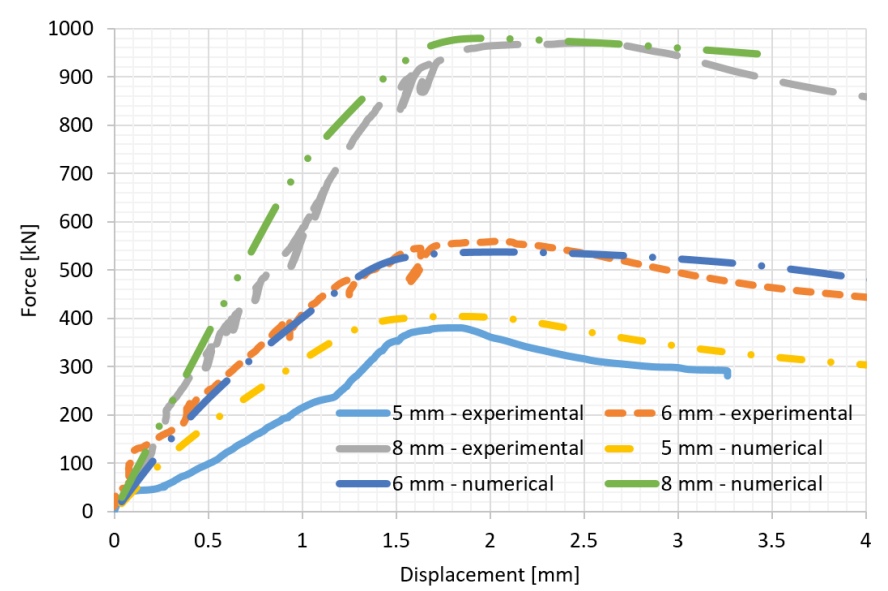

Fig. 11. Force-displacement relationship of 5, 6, and $8 \mathrm{~mm}$ specimens

The most important output from the analysis, in terms of the design solution, is the ultimate strength. The summary of the results is presented in Table 3. It can be seen that the results from the experimental testing and numerical estimation are quite similar. The most significant difference is observed for the $5 \mathrm{~mm}$ specimen, whereas the closest results were obtained in the $8 \mathrm{~mm}$ stiffened plate. The differences may originate from various sources. Almost clamped boundary conditions were achieved in the experimental testing. On the contrary, in the case of the numerical model, this was unachievable. Secondly, the mechanical properties presented in Table 1 are subject to some scatter, as shown in [28].

Tab. 3. Characteristics of tested stiffened plates

\begin{tabular}{|c|c|c|c|}
\hline \multirow{2}{*}{$\begin{array}{c}\text { Thickness } \\
{[\mathbf{m m}]}\end{array}$} & \multicolumn{2}{|c|}{ Ultimate force [kN] } & \multirow{2}{*}{ Difference [\%] } \\
\cline { 2 - 3 } & Experimental & Numerical & \\
\hline 5 & 380.2 & 403.8 & 5.9 \\
\hline 6 & 559.5 & 537.2 & -4.1 \\
\hline 8 & 969.9 & 979.7 & 1.0 \\
\hline
\end{tabular}

The post-collapse shapes obtained in the FE analysis are presented in Fig. 12. As can be seen, when compared to the experimental test (see Fig. 10), the forms of collapse are very close in general. However, for particular specimens, some differences can be observed. In the case of the $5 \mathrm{~mm}$ stiffened plate, the critical cross-section, where the highest deflections are observed, is near the middle in the case of the numerical model. It is located closer to the support in the experimental testing. The most similar forms are observed when considering the $6 \mathrm{~mm}$ specimen, including the critical cross-section and the shape of the collapsed stiffener. In the $8 \mathrm{~mm}$ stiffened plate, the region of the highest deflections is similar; however, some differences in the stiffener shape are observed. One of the possible reasons has been presented in [28], where it was shown that the non-uniform distribution of mechanical properties within a single specimen could affect both the ultimate strength and the post-collapse shape of the compressed stiffened plate. 

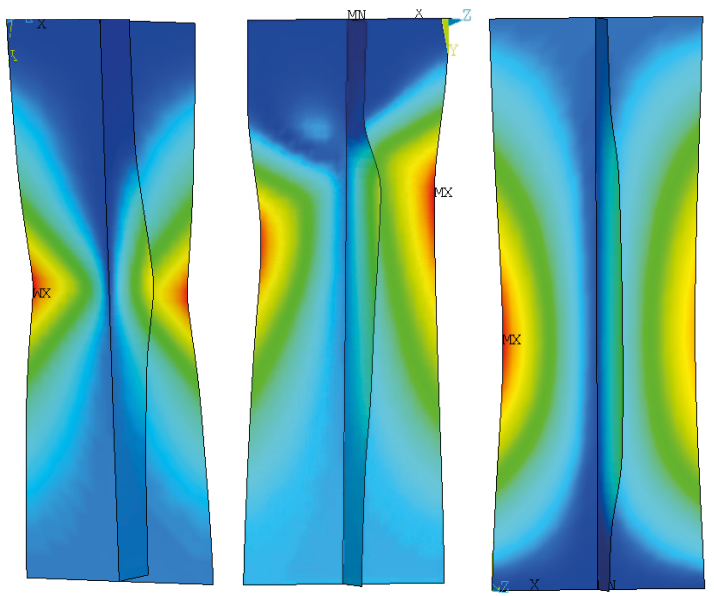

Fig. 12. FE model post-collapse shape for $5 \mathrm{~mm}$ (left), $6 \mathrm{~mm}$ (mid), and $8 \mathrm{~mm}$ (right) specimens

To investigate the structural behaviour during the entire loading process, selected strain measurements in the middle cross-section (see Fig. 1) were compared with the FE results. The results for the $5 \mathrm{~mm}$ stiffened plate are presented in Fig. 13.

The upper-left corner of Fig. 13 presents the strain of the edge of the specimen. It can be seen that, from the beginning of the loading process, the plate is subjected to bending. Up to the level of the ultimate strength, the strain measurements are very similar. After reaching the status of the highest compressive force, the strain in the experiment test decreases, whereas the strain in the FE analysis is still increasing. This indicates that before the ultimate strength was reached, the most significant bending occurred in a similar place, i.e., the middle of the specimen, caused by the shape of the imperfect stiffened plate. However, after reaching that point, in the FE model, the collapse occurred in this cross-section, leading to a significant strain. In the experimental test, the highest deflections shifted closer to the upper support (see Fig. 10), leading to the plate bending in the middle cross-section in the opposite direction and decreasing the strain. In the upperright corner of Fig. 13, the strain near the connection between the plate and stiffener is presented; in the upper and lower surface of the plate, these are almost identical.

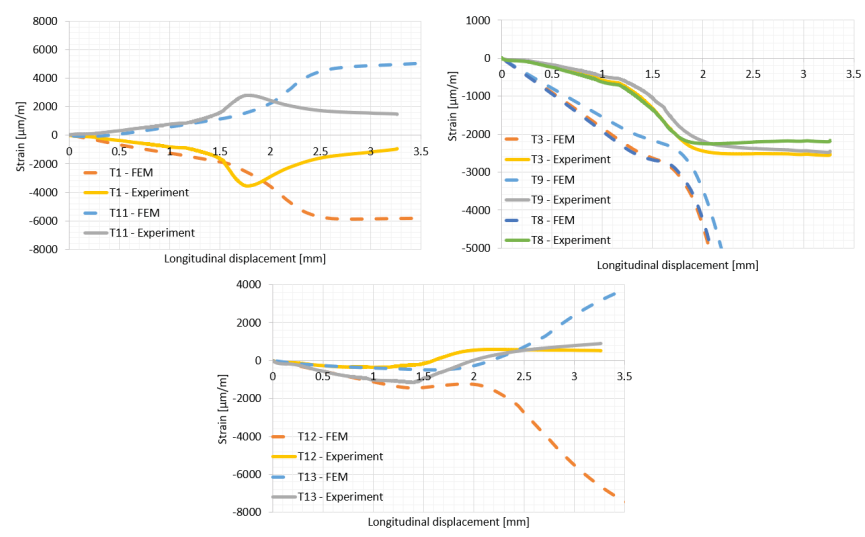

Fig. 13. Selected strains comparison for $5 \mathrm{~mm}$ specimen
This indicates that column buckling did not occur, and the local buckling of the plate dominates the collapse. These observations are consistent with the analysis of the postcollapse shape. The strain in the edge of the stiffener is presented at the bottom of Fig. 13. As can be observed, up to the moment when the maximum compressive force is reached, the strain readings are very similar for the experimental test and numerical computations.

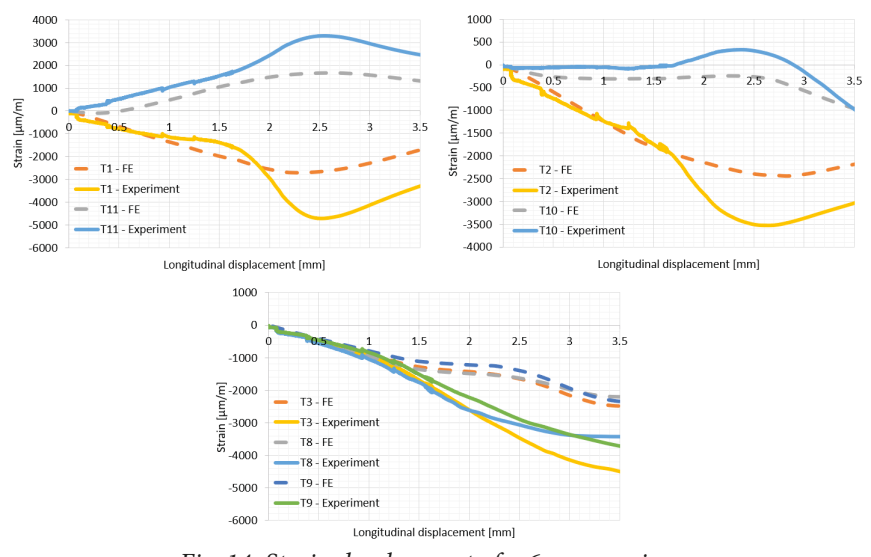

Fig. 14. Strain development of a $6 \mathrm{~mm}$ specimen

Fig. 14 shows the strain development of the $6 \mathrm{~mm}$ specimen. The strain in one of the longitudinal plate edges is shown in the upper-left corner in Fig. 14. Similarly, as was the case for the $5 \mathrm{~mm}$ specimen, the bending of the plate occurred from the very beginning of the loading process. However, in that case, when comparing the experimental and numerical measurements, the readings are very similar, which indicates that the structural behaviour during collapse was very similar. In the pre-collapse regime, the strain increases almost linearly. The decrease of the strain after the region of the highest compressive force is caused by the shift of the critical cross-section near the upper support.

Fig. 14, upper-right corner, shows the strain development of the plate between the edge and the stiffener. The observations are similar to those obtained for the strain gauges located on the edge of the plate. The only difference is that the plate transmits the axial compression, and the readings are unsymmetrical between the upper and bottom surface of the plate. The strain measured in the connection between the plate and stiffener is presented at the bottom of Fig. 14.

Similarly, to the specimen of $5 \mathrm{~mm}$ thickness, there is no significant difference between the strain in the upper and bottom surface of the plate, which indicates that local plate bending has been the primary cause of the collapse. 


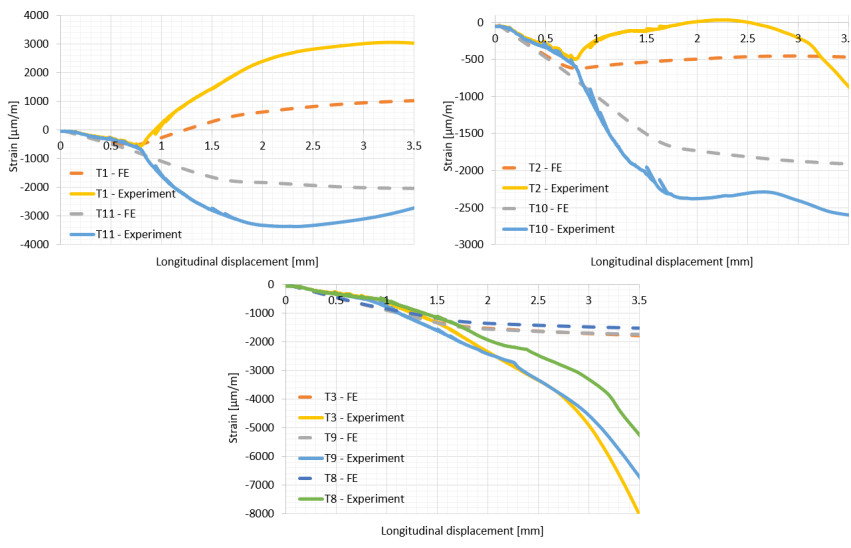

Fig. 15. Strain development of $8 \mathrm{~mm}$ specimen

The strain development of the $8 \mathrm{~mm}$ stiffened plate is presented in Fig. 15. In the upper-left corner of Fig. 15, the strain in the side-edge of the specimen is compared. It can be seen that up to the level of the longitudinal displacement of approximately $0.75 \mathrm{~mm}$, the plate was only subjected to the compressive load, and no bending was observed. In that region, the strain in the FE analysis and the tested specimen were the same. In the case of the $8 \mathrm{~mm}$ plate, local imperfections of the plate were insignificant. Thus, in the beginning, only an axial thrust was transmitted. After crossing that point, buckling occurred, and the strain increased rapidly due to the local bending of the plate created. It is also observed that the strain in the experimental test was considerably higher than the numerical estimation.

Relatively similar observations can be seen when one considers the strain in the plate between the edge and the stiffener, as presented in the upper-right corner of Fig. 15. However, the asymmetry of the readings is observed due to the higher contribution of the membrane stresses than in the plate edge (see Fig. 8). The strain in the middle of the specimen near the weld is presented at the bottom of Fig. 15. Similarly, to previous specimens, the strain in the upper and bottom surface of the plate is very close, showing that local plate buckling has dominated the collapse.

\section{COMPARISON BETWEEN EXPERIMENTAL RESULTS AND OTHER METHODS}

The method used to estimate the ultimate strength of the ship hull girder is the incremental-iterative approach as adopted by the Common Structural Rules [29]. The hull girder's ultimate strength is estimated based on the stressstrain responses of the stiffened plate and plate elements treated separately. The normalised ultimate strength of any individual stiffened plate is defined as the minimum from several possible failure modes: plastic collapse, local plate buckling, local stiffener tripping, or global column buckling and this formulation is used herein.
Additionally, the presented results are compared with the experimental results of Horne [7]. In this case, two flat-bar stiffened plates with similar plate and column slenderness ratios were found. Finally, the empirical formulation, as developed by Paik and Thaymballi [30], is used to compare the results presented in the current work. The numerical and experimental test results, as a function of the plate slenderness ratio, are presented in Fig. 16.

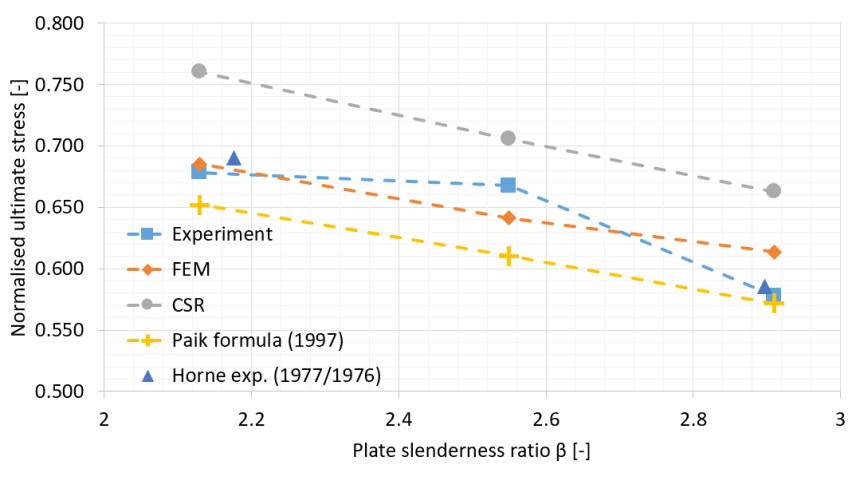

Fig. 16. Comparison of numerical and experimental results

It can be seen that, in the case of the stiffened plates with the lowest and highest values of the plate slenderness ratio, the presented analyses show results that are very close to the experimental results presented in [7]. In the case of Paik and Thaymballi' s empirical formulation [30], the normalised ultimate strength is lower concerning the experimental investigations presented in the current work. However, when considering the CSR formulation, it should be noted that it overestimates the ultimate strength estimated by FEM by up to $15 \%$.

\section{CONCLUSIONS}

Stiffened plates with different slenderness have been tested experimentally, and then a numerical analysis with the use of the FE method was performed. Pre-experimental analysis of both welding-induced residual stresses and initial imperfections was carried out, showing relatively low residual stresses and higher initial geometrical imperfections.

In all specimens, local plate buckling, followed by stiffener tripping, was the primary cause of the structural collapse. The analysis of the membrane strain in the plate revealed that the axial load is mainly transmitted by the region of the connection between the plate and the stiffener, and decreases near the side edges of the plate.

The developed numerical model was revealed to be an excellent tool in predicting the structural behaviour of stiffened plates subjected to compressive load, showing ultimate strength values very close to the experimental ones. The post-collapse forms were very similar. However, some differences were observed in the position of the collapsed cross-section where the highest deflections occurred and the shape of the collapsed stiffener. The possible reasons are 
related to the non-ideal clamped boundary conditions in the experimental testing and uncertainties in the mechanical properties. Comparison of the strain in the mid-cross-section revealed that, up to the point where the ultimate strength was reached, the agreement between the numerical and experimental results was good. In the case of the $5 \mathrm{~mm}$ and $6 \mathrm{~mm}$ specimens, bending of the plate occurred from the beginning of the loading process, due to a high level of initial imperfections compared to the plate thickness. In the $8 \mathrm{~mm}$ specimen, the level of imperfections was not that high, and the local plate bending occurred above a certain compressive force.

The experimental and numerical investigations were compared with results published in the literature and showed good agreement. However, it was revealed that the formulation used in the Common Structural Rules overestimates the ultimate strength of stiffened plates.

In future work, the structural behaviour of stiffened plates, accounting for different degradation effects such as corrosion degradation and cracking, will be investigated. The analyses presented here will establish the basis for the next experimental analysis by providing information about the strength characteristics of intact non-corroded stiffened plates.

\section{ACKNOWLEDGEMENTS}

This work was supported by the National Science Centre, Poland (grant No. 2018/31/N/ST8/02380). The ANSYS software used in the simulations presented in this paper was available as part of the partnership cooperation agreement between ANSYS Inc., MESco sp. z o.o., and the Gdansk University of Technology.

\section{REFERENCES}

1. M. Taczala, "Approximate method for evaluation of stressstrain relationship for stiffened panel subject to tension, compression and shear employing the finite element approach," Proc. MARSTRUCT 2009, 2nd Int. Conf. Mar. Struct. Des. Mar. Struct., 2009. pp. 155-61.

2. J. Czujko, A. Bayatfar, M. Smith, M. Xu, D. Wang, M. Lützen et al., "Committee III.1: Ultimate Strength," in: M. Kaminski, P. Rigo, Eds. Proc. 20th Int. Sh. Offshore Struct. Congr. (ISSC 2018), vol. 1, IOP Press; 2018. pp. 335-439.

3. D.W.Lang, W.G. Warren, "Structural strength investigations on the destroyer Albuera," Trans. Inst. Nav. Arch., vol. 94, pp. 243-86, 1952.

4. Y. Wang, S. Xu, A. Li, "Flexural performance evaluation of corroded steel beams based on 3D corrosion morphology," Struct. Infrastruct. Eng., vol. 16, pp. 1-16, 2020.
5. D. Faulkner, "A review of effective plating for use in the analysis of stiffened plating in bending and compression," J. Sh. Res., vol. 19, pp. 1-17, 1975.

6. K. Woloszyk, Y. Garbatov, "Analysis of ultimate compressive strength of cracked plates with the use of DOE techniques," Polish Marit. Res., vol. 27, pp. 109-20, 2020.

7. M. Horne, R. Narayanan, "Ultimate capacity of stiffened plates used in girders," Proc. Inst. Civ. Eng., vol. 61(2), pp. 253-80, 1976.

8. M.R. Manco, M.A.Vaz, J.C.R. Cyrino, N.M. Ramos, D.A. Liang, "Experimental and numerical study of uniaxially compressed stiffened plates with different plating thickness," Thin-Walled Struct., vol. 145, p. 106422, 2019.

9. O. Ozguc, "Assessment of buckling behaviour on an FPSO deck panel," Polish Marit. Res., vol. 27, pp. 50-8, 2020.

10. P. Dowling, S. Chatterjee, P.A. Frieze, F.M. Moolani, "Experimental and predicted collapse behaviour of rectangular steel box girders," Int. Conf. on Steel Box Girder Bridges, London: Institute of Civil Engineers, 1973. pp. 77-94.

11. S. Saad-Eldeen, Y. Garbatov, C. Guedes Soares, "Ultimate strength assessment of corroded box girders," Ocean Eng. vol. 58, pp. 35-47, 2013.

12. S. Saad-Eldeen, Y. Garbatov, C. Guedes Soares, "Experimental assessment of the ultimate strength of a box girder subjected to severe corrosion," Mar. Struct., vol 24, pp. 338-57, 2011.

13. S. Saad-Eldeen, Y. Garbatov, C.G. Soares, "Corrosiondependent ultimate strength assessment of aged box girders based on experimental results," J. Sh. Res., vol. 55, pp. 289-300, 2011.

14. S. Xu, B. Liu, Y. Garbatov, W. Wu, C. Guedes Soares, "Experimental and numerical analysis of ultimate strength of inland catamaran subjected to vertical bending moment," Ocean Eng., vol. 188, p. 106320, 2019.

15. J. Wang, S. Zang, "Ultimate strength experimental research for longitudinal box girders module model," Shipbuilding China, vol. 2, p.008, 2011.

16. K. Woloszyk, Y. Garbatov, J. Kowalski, L. Samson, "Numerical and experimental study on effect of boundary conditions during testing of stiffened plates subjected to compressive loads," Eng. Struct. 2020, submitted for publication.

17. K. Woloszyk, Y. Garbatov, "FE analysis of supportspecimen interaction of compressive experimental test," 
in: Sustainable Development and Innovations in Marine Technology, P. Georgiev, C.G. Soares, Eds. CRC Press, 2019, pp. 423-8.

18. S. Zhang, "A review and study on ultimate strength of steel plates and stiffened panels in axial compression," Ships Offshore Struct., vol. 11(1), pp. 81-91, 2015.

19. M. Chmielewski, L. Piotrowski, B. Augustyniak, "A fast procedure of stress state evaluation in magnetically anisotropic steels with the help of a probe with adjustable magnetizing field direction," Meas. Sci. Technol., vol. 28, p. $045903,2017$.

20. Y. Garbatov, C. Guedes Soares, K. Masubuchi, "Residual stresses and distortion in welds," in: Reference Modules in Materials Science and Materials Engineering, Elsevier, 2016.

21. ANSYS. Online Manuals, Release 192019.

22. K. Woloszyk, Y. Garbatov, "Uncertainty assessment of ultimate strength of corroded stiffened plates subjected to maintenance," in: Sustainable Development and Innovations in Marine Technology, P. Georgiev, C. Guedes Soares, Eds. CRC Press, 2019, pp. 429-36.

23. T. Urbański, A. Banaszek, W. Jurczak, "Prediction of welding-induced distortion of fixed plate edge using design of experiment approach," Polish Marit. Res., vol. 27, pp. 134-42, 2020.

24. T. Urbański, M. Taczała, "Prediction of a transverse shrinkage of butt welded joints in shipyard conditions using the design of experimental approach," Int. J. Nav. Archit. Ocean Eng., vol. 12, pp. 784-98, 2020.

25. B.Q. Chen, Y. Garbatov, C. Guedes Soares, "Measurement of weld-induced deformations in three-dimensional structures based on photogrammetry technique," J. Sh. Prod., vol. 27, pp. 51-62, 2011.

26. K. Woloszyk, P. Bielski, Y. Garbatov, T. Mikulski, "Photogrammetry image-based approach for imperfect structure modelling and FE analysis," 2020, manuscript in preparation.

27. J. Cui, D. Wang, "An experimental and numerical investigation on ultimate strength of stiffened plates with opening and perforation corrosion," Ocean Eng., vol. 205, p. 107282,2020

28. K. Woloszyk, Y. Garbatov, "Ultimate strength of stiffened plates subjected to compressive load and spatially distributed mechanical properties," in: Proceedings MARTECH 2020, 2020, (accepted for print).
29. International Association of Classification Societies. Common Structural Rules (BC \& OT). 2018.

30. J.K. Paik, A.K. Thayamballi, "Empirical formulation for predicting the ultimate compressive strength of stiffened panels," Proc. Int. Offshore Polar Eng. Conf., 1997.

\section{CONTACT WITH THE AUTHORS}

\author{
Krzysztof Woloszyk \\ e-mail:krzwolos@pg.edu.pl
}

Gdansk University of Technology,

Faculty of Ocean Engineering and Ship Technology,

Narutowicza 11/12, 80-233 Gdańsk,

Poland

Yordan Garbatov

e-mail:yordan.garbatov@tecnico.ulisboa.pt

Centre for Marine Technology and Ocean Engineering (CENTEC),

Instituto Superior Técnico, Universidade de Lisboa, Avenida Rovisco Pais, 1049-001 Lisboa,

\section{Portugal}

Jakub Kowalski

e-mail:jakkowal1@pg.edu.pl

Gdansk University of Technology,

Faculty of Ocean Engineering and Ship Technology,

Narutowicza 11/12, 80-233 Gdańsk,

\section{POLAND}

Leszek Samson

e-mail:lessamso@pg.edu.pl

Gdansk University of Technology,

Faculty of Ocean Engineering and Ship Technology,

Narutowicza 11/12, 80-233 Gdańsk,

\section{Poland}

